\title{
Introduction
}

\section{In Memorium: Professor David S Segal}

\author{
\begin{tabular}{l}
\hline Lewis L Judd*,', Ronald Kuczenski', Marc Schuckit' and Neal Swerdlow' \\
'Department of Psychiatry, University of California, San Diego, La Jolla, CA, USA
\end{tabular} \\ Neuropsychopharmacology (2006) 3 I, 233I. doi: I0.1038/sj.npp. I 30 I I58; published online 19 July 2006
}

A substantial portion of the following issue of Neuropsychopharmacology is devoted as a memorial to Professor David S Segal, a long-time Fellow in the American College of Neuropsychopharmacology and a member of the Departments of Psychiatry and Neurosciences at the University of California, San Diego, for over 36 years. David Segal tragically and prematurely passed away on August 23, 2005, after a surprisingly short and aggressive course of pancreatic cancer. He died at peace surrounded by his family: his loving wife, Betsy Morris; children, Jennifer Diascro, Julie Fallon, and Jeffrey Segal; and his stepchildren, Anna and Nick Slutsky. Also of comfort were his children's spouses, Mathew Diascro, William Fallon, Christine Segal, and Ian Lowe; and two grandchildren, Roman and Benjamin.

The course of his illness was so swift that friends and colleagues both at UCSD and in other parts of the country were unable to organize a Festschrift to recognize and honor him for his many innovative scientific contributions and prodigious efforts in the field of neuropsychopharmacology. His commitment to scientific quality was legendary and his standards of personal and scientific conduct were always above reproach. He was a nationally and internationally known expert and creative scientific leader who studied the long-term effects of drugs on the brain and behavior and the resulting neurochemical mechanisms of adaptation. By every criteria of scientific and pedagogical achievement, he was a highly successful scientist and academic, having an unbroken track record of peer-reviewed research funding from the NIH throughout his entire career and was an NIH Research Scientist Awardee for over 20 years. His body of work featured groundbreaking innovative research strategies as well as important methodological advances. Specifically, he conducted fundamental investigation in the effects of CNS stimulants on the brain providing a basis for understanding the mechanisms of drug-induced psychosis and mania, and the therapeutic action of stimulants in attention-deficit hyperactivity disorder. He was a prolific research scientist, publishing 179 papers and chapters in high-quality

\footnotetext{
* Correspondence: Dr LL Judd, Department of Psychiatry, University of California, San Diego, 9500 Gilman Drive, La Jolla, CA 92093-0603, USA, Tel: + I 858534 3684, Fax: + I 8585347653 ,

E-mail: ljudd@ucsd.edu
}

scientific journals and invited prestigious review monographs.

Because he was an inherently fair-minded, highly ethical, wise, intelligent, scientifically productive, and humane man, he was an ideal person to serve as an extraordinarily active and valued teacher and mentor to graduate students, postdoctoral trainees, and young faculty in psychiatry, neuroscience, and pharmacology. He was revered as a consummate mentor for students and trainees, many of whom have gone on to distinguished scientific careers in various academic institutions throughout the country. In lieu of a Festschrift, David's friends, both in the Department and elsewhere, many of whom are members and Fellows of the ACNP, feel that a lasting honor in memoriam of our dear friend is the following volume in his name, which highlights a number of his past students, trainees, and collaborators.

The following seven manuscripts were contributed by David's former students and Fellows and are a testimony to the impact of David's generativity, across a wide range of topics within neuropsychopharmacology. The issue begins with detailed and thoughtful reviews of the basic neuroscience of stimulant effects on arousal (Berridge), and on the electrophysiological correlates of behavioral activation (Rebec). The next papers have their origins in an area of inquiry common to many of David's studies: the neuropharmacology of stimulant effects on rodent behavior. These manuscripts leverage advanced applications of molecular genetics to reveal new and important insights into mechanisms by which dopamine receptor subtypes regulate stimulant-induced locomotor patterns (Geyer et al), stereotyped behaviors (Shilling et al), and behavioral sensitization (Richtand). While David's studies on stimulant sensitization had their most direct clinical influence in the area of substance use disorders, the final two papers in this issue by David's students reveal his broader clinical legacy, which has impacted topics ranging from the therapeutic actions of stimulants in attention-deficit hyperactivity disorder (Arnsten), to the neural basis for therapeutic manipulations of basal forebrain circuitry in obsessive compulsive disorder (Greenberg et al).

This special issue was organized with input from David's ACNP friends and colleagues at UCSD and the articles were complied and edited by Marc Schuckit, MD and Neal Swerdlow, MD, PhD. 